\title{
Pengembangan Media Pembelajaran Berbasis Video Sparkol Dengan Menggunakan Media Internet Dalam Pembelajaran Matematika SMP Negeri 1 dan 2 Kecamatan Tanah Jawa
}

\author{
Imeldawaty Gultom $^{1}$, Marto Sihombing ${ }^{2}$ \\ Email : imeldagultom81@gmail.com ${ }^{1}$, martosihombing45@gmail.com² \\ 1,2 Program Studi Teknik Informatika STMIK Kaputama \\ Jl. Veteran No. 4A-9A, Binjai, 20714, Sumatera Utara
}

\begin{abstract}
Abstrak
Keberadaan internet dan segala fasilitas yang ada dapat memberikan pengetahuan baru ataupun menelusuri bahan ajar bagi guru sehingga internet sebagai media pembelajaran yang lebih mudah dan dapat memperkaya wawasan guru. Penelitian ini bertujuan untuk mengetahui pemanfaatan video sparkol sebagai sumber belajar bagi Guru matematika SMP Negeri Kecamatan Tanah Jawa. Media pembelajaran internet berbasis video sparkol dibuat dengan aplikasi videoscribe, sebagai media pembelajaran yang dapat digunakan dalam sekolah maupun diluar sekolah. Penelitian bermaksud mengembangkan media pembelajaran yang dapat diakses secara bebas di Internet. Model pembelajaran internet berbasis video sparkol yang digunakan adalah videoscribe yang bersifat terbuka dan massal. Kurikulum pembelajaran juga menyediakan seperangkat alat pembelajaran meliputi, berbagai soal, kuis, dan bentuk- bentuk penugasan. Langkah-langkah pelaksanaan penelitian mengikuti pola umum penelitian ilmiah dengan pendekatan berorientasi obyek dengan tahapan identification (identifikasi), analysis (analisis), design (perancangan), coding (pemrograman) dan testing (pengujian). Penelitian ini menghasilkan luaran yang ditargetkan pada hasil penelitian ini adalah berupa artikel yang akan dipublikasi pada Jurnal Nasional Terakreditasi. Artikel ini juga bertujuan untuk menyebarluaskan hasil penelitian dan ilmu pengetahuan yang dapat dimanfaatkan untuk menambah wawasan dan pengembangan ilmu pengetahuan ke depannya terutama dalam menemukan aturan asosiasi antar indikator pencapaian standar kompetensi yang diujikan pada mata pelajaran matematika.
\end{abstract}

Kata Kunci: Internet; Media Pembelajaran; Sparkol; VideoScribe.

\begin{abstract}
The existence of the internet and all existing facilities can provide new knowledge or browse teaching materials for teachers so that the internet is an easier learning medium and can enrich teachers' insights. This study aims to determine the use of sparkol video as a learning resource for mathematics teachers of SMP Negeri Tanah Jawa District. Sparkol video-based internet learning media is made with the Videoscribe application, as a learning medium that can be used in schools and outside of school. The research aims to develop learning media that can be accessed freely on the Internet. Sparkol video-based internet learning model used is videoscribe which is open and mass. The learning curriculum also provides a set of learning tools covering, various questions, quizzes, and forms of assignments. The research implementation steps follow the general pattern of scientific research with an object-oriented approach with the stages of identification (identification), analysis (analysis), design (design), coding (programming) and testing (testing).

This study produced an outcome that was targeted at the results of this study in the form of articles to be published in an Accredited National Journal. This article also aims to disseminate the results of research and science that can be used to broaden the knowledge and development of science in the future, especially in finding association rules between indicators of achieving competency standards tested in mathematics.
\end{abstract}

Keywords: Internet; Learning Media; Sparkol; VideoScribe.

\section{PENDAHULUAN}

Indonesia merupakan negara yang mendukung penuh pelaksanaan pendidikan, karena pendidikan merupakan pendukung agar masyarakat maju dan makmur. Media pendidikan 
dimanfaatkan seseorang agar dapat mempunyai kemampuan, pengetahuan dan sumber daya manusia yang tinggi yang berkompetendi. Hal-hal tersebutlah menjadi salah satu modal manusia agar dapat bertahan hidup dan bersaing di era modern seperti sekarang ini [1].

Kemajuan teknologi dan telekomunikasi (TIK) yang maju semakin pesat akan menghasilkan berbagai kemudahan dalam melakukan dan mengembangkan teknik pembelajaran yang inovatif sehingga akan menghasilkan keluaran yang baik dan berkualitas. Demikian halnya pada peserta didik, dengan teknologi dan multimedia diharapkan akan memudahkan bagi mereka dalam menentukan dengan apa dan bagaimana untuk dapat menyerap informasi secara efektif dan efisien.

Pada saat ini konsep pendidikan harus didominasi oleh peserta didik atau student centre, berbeda dengan dulu yakni teacher centre. Peserta didik diberikan kesempatan untuk berinteraksi di dalam kelas dengan sumber belajar maupun dengan teman sekelas. Para siswa yang mengikuti program pendidikan diharapkan mampu melakukan analisis untuk menyimpulkan pembelajaran, sehingga para siswa menjadi lebih aktif di dalam kelas [1].

Terselenggaranya pendidikan akan membuat siswa sebagai manusia mampu saling bertukar permasalahan, informasi menciptakan generasi penerus bangsa yang berkompeten dan berkualitas, memperdalam suatu ilmu pengetahuan, mengoptimalkan sumber daya manusia, membentuk karakter bangsa, memperbaiki cara berpikir individu, meningkatkan taraf hidup seseorang, mencerdaskan anak bangsa dan meningkatkan kreativitas.

Masalah dalam penelitian didapat berdasarkan hasil wawancara dengan guru bidang studi matematika di dua sekolah SMP Negeri 2 Tanah Jawa dan SMP Negeri 1 Tanah Jawa pada tanggal 15 Januari 2019 hasil belajar siswa pada materi peluang dan statistik siswa mengalami kesulitan untuk dapat memahami pembelajaran khususnya dalam memecahkan soal-soal tentang peluang dan statistik.

Pemakaian media pembelajaran dalam proses belajar mengajar dapat membangkitkan motivasi pada siswa [2], karena video Sparkol merupakan sebuah media pembelajaran video animasi yang terdiri dari rangkaian gambar yang disusun menjadi sebuah video utuh [3], yang dapat menampilkan/menyajikan konten pembelajaran dengan memadukan grafik, gambar, suara, sehingga desain menjadi menarik dan mahasiswa menjadi mampu menikmati proses pembelajaran [4].

\section{METODE PENELITIAN \\ Desain Penelitian}

Peneliti menggunakan pola one- group pretest- posttest design dalam menguji hasil media yang telah dikembangkan, dimana hanya terdapat suatu kelompok yang diberi treatment. Desain ini menggunakan dua kali perlakuan yaitu sebelum menggunakan media dan setelah menggunakan media. Observasi yang dilakukan sebelum eksperimen yaitu pretest. Sedangkan observasi setelah eksperimen yaitu posttest. Desain ini menggunakan rumus : O1 X O2, dimana O1 adalah Pretest, $\mathrm{X}$ adalah Treatment, dan $\mathrm{O} 2$ adalah Posttest [9].

Adapun tahapan-tahapan dalam model pengembangan adalah sebagai berikut:

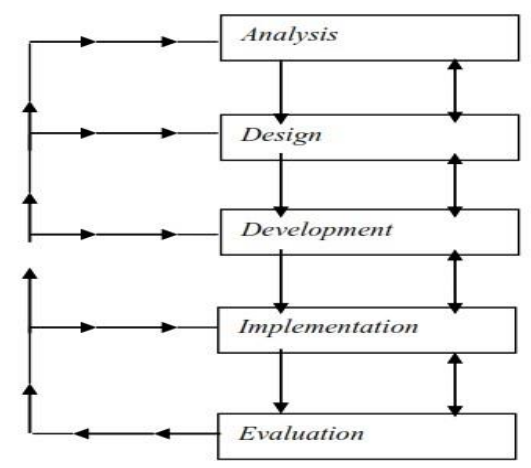

Gambar 1. Model Pengembangan ADDIE 
Penjelasan dari model pengembangan adalah sebagai berikut:

1. Analisis

Analisis, merupakan proses mengidentifikasi masalah pada tempat yang dijadikan sampel penelitian.

2. Desain

Desain merupakan tahap pembuatan rancangan tampilan media yang akan dikembangkan dan alur navigasi media. Dalam penelitian ini desain merupakan tahap pembuatan peta kompetensi, peta materi,

3. Pengembangan

Pengembangan adalah tahap pembuatan media sesuai dengan rancangan media pada tahap desain. Dalam penelitian ini, tahap pengembangan merupakan tahap produksi media. Selain itu pada tahap ini media direvisi oleh ahli media dan ahli materi agar mendapat perbaikan setelah itu divalidasi kelayakannya untuk digunakan di dalam pembelajaran. Media divalidasi oleh ahli media dan ahli materi dengan menggunakan angket yang telah disediakan oleh peneliti.

4. Implementasi

Implementation, langkah nyata untuk menerapkan media pembelajaran yang sudah dibuat. Sesuai dengan sasarannya, produk ini akan diimplementasikan di SMP.

5. Evaluasi

Tahap ini merupakan tahap produksi media dimana pembuatan media disesuaikan dengan naskah yang telah dirancang. Pada tahap ini juga media yang telah selesai dibuat diperiksa dan divalidasi oleh ahli media dan ahli materi agar dapat digunakan di dalam pembelajaran.

\section{HASIL PENELITIAN}

Ketika aplikasi web browser googlecrome pada alamat https://www.videoscribe.co/en/login/profil e\# maka akan tampil halaman utama seperti pada gambar 2

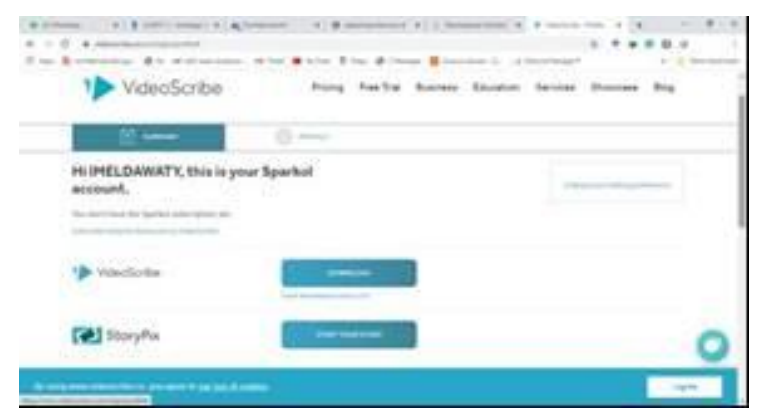

Gambar 2. Video Sparkol/Srcibe

\subsection{Tahap Disain}

Pada tahapan ini merupakan tahap persiapan pembuatan media pembelajaran dengan membuat materi dan naskah media berdasarkan silabus mata pelajaran Matematika.

\subsection{Development}

Tahap ini merupakan tahap produksi media dimana pembuatan media disesuaikan dengan naskah yang telah dirancang. Pada tahap ini juga media yang telah selesai dibuat diperiksa dan divalidasi oleh ahli media dan ahli materi agar dapat digunakan di dalam pembelajaran. 
4.3.1 Tampilan Awal Video Bagian ini merupakan tampilan awal dari media pembelajaran menggunakan sparkol videoscribe dengan menampilkan judul isi video dan nama pembuat video.

Berikut adalah hasil visualisasi media pembelajaran menggunakan sparkol videosribe yang ditampilkan pada gambar 3 .

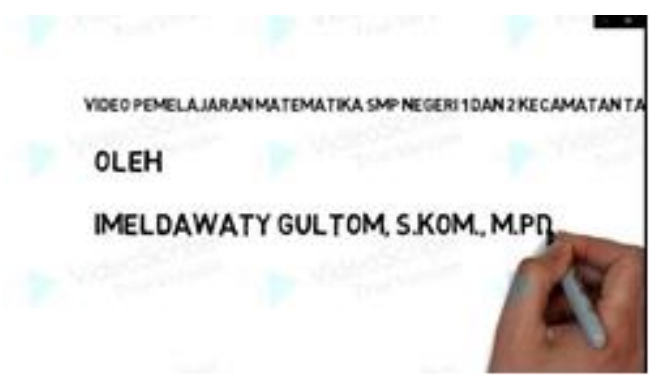

Gambar 3. Tampilan awal video

4.3.2 Tampilan Bentuk Segitiga Bagian ini merupakan tampilan dari media pembelajaran menggunakan sparkol videoscribe dengan menampilkan gambaran dari bentuk segitiga. Berikut adalah hasil visualisasi media pembelajaran menggunakan sparkol videosribe yang ditampilkan pada gambar 4 .

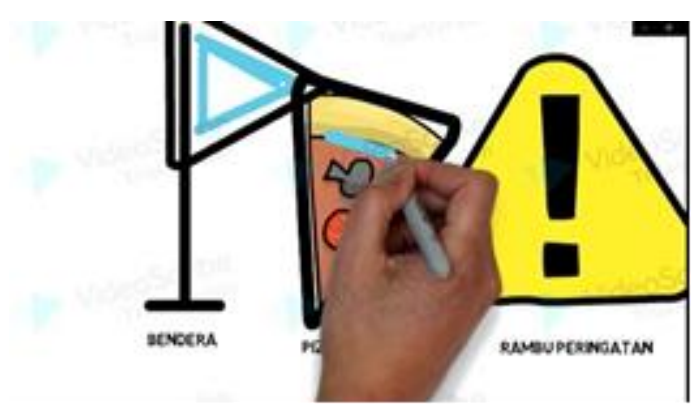

Gambar 4. Bentuk Segitiga

\subsubsection{Tampilan Pengertian Segitiga}

Bagian ini merupakan tampilan dari media pembelajaran menggunakan sparkol videoscribe dengan menampilkan pengertian dari bentuk segitiga. Berikut adalah hasil visualisasi media pembelajaran menggunakan sparkol videosribe yang ditampilkan pada gambar 5.

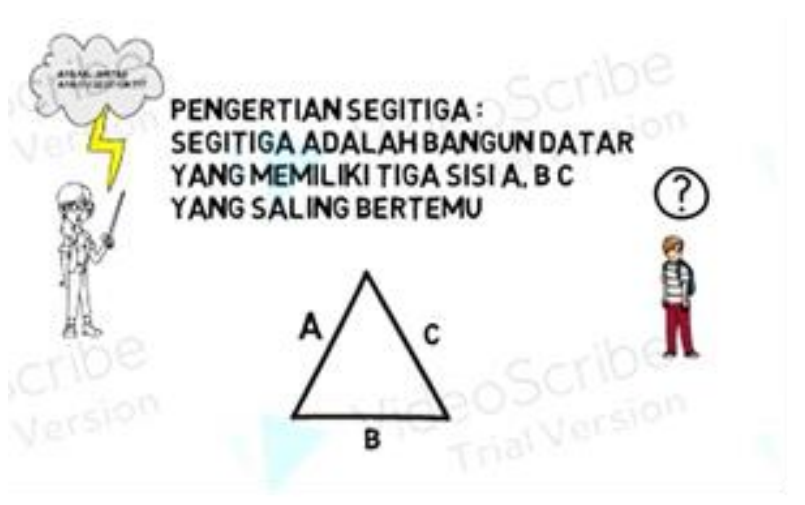

Gambar 5. Pengertian Segitiga 
4.3.4 Tampilan Jenis Segitiga Bagian ini merupakan tampilan dari media pembelajaran menggunakan sparkol videoscribe dengan menampilkan dari jenis segitiga. Berikut adalah hasil visualisasi media pembelajaran menggunakan sparkol videosribe yang ditampilkan pada gambar 6 .

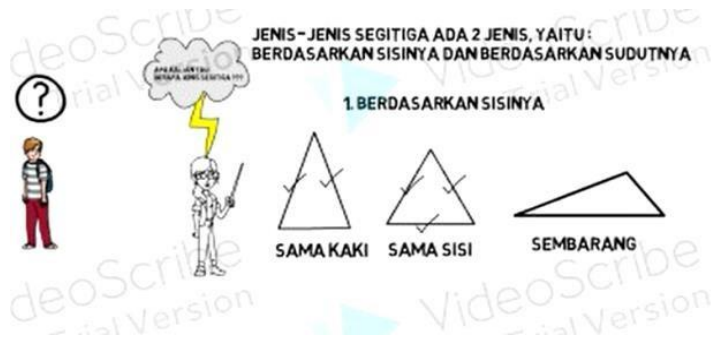

Gambar 6. Jenis Segitiga

\section{KESIMPULAN}

Berdasarkan hasil penelitian dan pembahasan yang telah diuraikan dalam penelitian ini, maka dapat disimpulkan sebagai berikut:

1. Karena rendahnya minat belajar para siswa SMP, maka dilakukan pengembangan media pembelajaran menggunakan sparkol videoscribe. Hal ini terjadi disebabkan oleh karena guru kurang menyediakan media pembelajaran sehingga pembelajaran menjadi membosankan dan siswa kurang memperhatikan materi yang sedang dijelaskan.

2. Media pembelajaran menggunakan sparkol videoscribe dianggap layak untuk diterapkan dalam pembelajaran di kelas.

3. Penggunaan media pembelajaran menggunakan sparkol videoscribe berhasil meningkatkan minat belajar siswa.

\section{DAFTAR PUSTAKA}

[1] Kholidin and S. S. Hudaidah, "Pengembangan Media Pembelajaran Menggunakan Program Video Scribe Sparkol Pada Mata Pelajaran Sejarah Kelas Xi Di Sekolah Menengah Atas,” J. Institusi, 2017.

[2] A. Azhar, "Media Pembelajaran," Meedia Pembelajaran, 2008, doi: media pembelajaran.

[3] D. F. Rahmatika and N. Ratnasari, "Media Pembelajaran Matematika Bilingual Berbasis Sparkol Videoscribe," Desimal J. Mat., vol. 1, no. 3, pp. 385-393, Sep. 2018, doi: 10.24042/djm.v1i3.3061.

[4] D. Arwudarachman, W. Setiadarma, and Marsudi, "Pengembangan Media Pembelajaran Audio Visual untuk Meningkatkan Prestasi Belajar Menggambar Bentuk Siswa Kelas XI,” J. Pendidik. Seni Rupa, 2015.

[5] A. S. Sadiman, R. Rahardjo, and A. Haryono, Media pendidikan pengertian, pengembagan, dan pemanfaatan. 2014.

[6] Oemar Malik, "Pembuatan Media Pembelajaran Biologi Untuk Kelas Viii Sekolah Menengah Pertama Negeri 1 Tasikmadu," Semin. Ris. Unggulan Nas. Inform. dan Komput. FTI UNSA Maret, 2003.

[7] Syaiful Bahri Djamarah, "Strategi Belajar Mengajar. Jakarta: PT Rineka Cipta," Syaiful Bahri Djamarah dan Aswan Zain, 2006, doi: 10.1016/j.bbapap.2013.06.007. 
ALGORITMA: Jurnal Ilmu Komputer dan Informatika

Volume: 04, Number: 02, November 2020 ISSN 2598-6341 (online)

[8] A. Azhar, "Media pembelajaran; Edisi revisi," 2008

[9] Sugiyono, Metode Penelitian Kombinasi (mixed Methods ). 2018. 